\title{
Simulation of Chemical Attack on the Population and its Protection
}

\author{
Marta Blahova \\ Tomas Bata University in Zlín \\ Nad Stráněmi 4511,760 05 Zlín, Czech Republic \\ m6_blahova@utb.cz \\ Martin Hromada \\ Tomas Bata University in Zlín \\ Nad Stráněmi 4511,760 05 Zlín, Czech Republic \\ hromada@utb.cz
}

\begin{abstract}
The article focuses on the basic security aspects of population protection against chemical terrorism. The introduction is focused on the definition of security and the general characteristics of security documents. The last passages of the texts are focused on publishing the issue of terrorism, ensuring a special approach to the subject of the article put on the field of chemical terrorism, and the theory of the protection of the population against chemical terrorism. The introductory part of the article describes the various means of chemical terrorism, the threat of part of the weapons is presented in the fight against chemical substances. Greater risk can be applied to chemicals that are available to the advertiser for modeling in the TerEx software program. The conclusion of the article is a sign of evaluation of population protection and submission of its proposals for possible improvement of the current situation. instructions give you basic guidelines for preparing cameraready papers.
\end{abstract}

Index Terms-Security, chemical terrorism, population protection, chemicals.

\section{INTRODUCTION}

Humanity has been interested in existence since it was forced to face various adverse influences. As time goes on, the supply of these negative circumstances seems to have an increasing tendency. Stress, busy times and the rapid evolution of today's influential people's behavior is the reason why I present one of the greatest threats to mankind today. Right to life and its protection of fundamental human rights. Protecting the population by seeking a substantial part of the security of each state. Despite its quality in different countries on different borders and objectives, it is not possible to formulate and uniform protection for all. No country is required to face different threats and systems for all countries by being inefficient and sufficient for the weak. The current state

Footnotes: 8-point Times New Roman font;

Manuscript received July 1, 2012; revised August 1, 2012; accepted September 1, 2012.

Copyright credit, project number, corresponding author, etc. of population protection is dependent on the historical development of population protection, which looks different in different countries.

Violence has become an accompanying phenomenon of every human community in infinitely many forms, depending on economic, political, religious and other conditions. A chemical terrorist attack is a phenomenon that exceeds the danger of using firearms with its destructive potential. Chemicals can reach dangerous hands from various sources. Their often not very complicated availability is one of the features of today. Despite the existence of the International Convention on the Prohibition of Chemical Weapons, there are still the last stocks in the world that have not yet been destroyed. Against this background, the use of weapons of mass destruction, including chemical weapons, is currently considered a major global threat to society. The preparedness of the population for chemical terrorism is currently not fully adequate.

This is because the population is not sufficiently aware of the risks posed by chemical terrorism. A particular spectrum of people does not even know that there are other variants of terrorism besides the classical form of terrorism. A prepared man can help not only himself but also his surroundings and is also capable to better estimate the whole situation. Another important benefit of the prepared person is his smooth and trouble-free cooperation with the components of the integrated rescue system, which will deal with a possible chemical attack. For these reasons, it is impossible to determine to what extent which country is ready to face such a threat. Individual exercises by security forces and authorities may indicate sufficient preparedness, but this can only be verified when the threat arises.

\section{METHODS USED OF PROCESSING} III.

This article is for users. The first one is a more extensive amount of theory that will serve as a general basis for introducing the issue. The processing is drawn from available domestic and foreign sources. The 
resulting theoretical part should fulfill an informative purpose.

The second sub-objective consists of processing model situations on a reduced topic using a software program. Several industrial and chemical substances were used for modeling. The purpose is expected in the context of preavailable data information on possible chemicals. These chemicals were prepared under the given conditions as the best option in case of a terrorist attack.

The last part is an evaluation and own proposal to evaluate the issue of protection of the population against chemical terrorism.

The following methods are used to process the article:Analysis - It is the analysis of properties, relationships, facts. It proceeds from whole to parts.

- Deduction - It is the progress from less general to more general. This progress is closely related to induction.

- Induction - Generating a general (theoretical) conclusion based on knowledge of details. Induction allows the nature of phenomena to be established and to determine their patterns.

- Generalization - It is a process of finding a summary, common characteristic for a class of phenomena, or the formulation of a universally valid statement.

- Synthesis - It means to progress from part to whole, where the basis is understanding the interconnection of phenomena.

- Modeling - It allows simulating (display) reality using a model (simulation).

\section{SAFETY OF THE POPULATION}

The security of the population has been and will always be the primary possible state. Priority is given to protecting the lives, health, safety of people, property, the environment, critical infrastructure and the existence of the state. In today's advanced society, they face various threats that can or indirectly affect the functioning of society. In order to maintain safety, long-term and systematic work must be carried out on the risk of maintenance. The term security allows the terminology to be a "state where the system is threatening known and predictable (and unexpected) external and internal threats that negatively affect individual elements (or the whole system) in order to maintain the system structure, stability, reliability, and behavior in accordance with the targets. It is, therefore, a measure of the stability of the system and its possible and secondary adaptations. [1]

\section{CHEMICAL TERRORISM AND THE}

Pterrorism was not considered a threat; The breakthrough in the perception of terrorism occurred only in connection with the attack on the United States on September 11, 2001, when its destructive power was first demonstrated in full force. In various possibilities and negative inputs easier to all areas of social activities and whirling knowledge and threatening phenomenon of the $21 \mathrm{st}$ century. [2] Following the terrorist attacks in September 2001, a framework for combating terrorism at the
European Union level was created almost immediately. Conclusions on security and other measures to be taken in the fight against terrorism were adopted. Based on these conclusions, the Council of the European Union decided in December of the same year to adopt a framework for combating terrorism at the European Union level, with the main benefit of this framework being a standard, universally acceptable definition of terrorism and harmonization of sanction mechanisms for suspected terrorists. [2]

The term terrorism is difficult to define precisely. It can be understood as a direction that uses coercion, psychological or physical violence, threats, creating an atmosphere of fear and panic, extortion of state authorities and other methods to achieve political, national or other goals. Most often, terrorism is defined as: "Planned, thought-out and politically motivated violence directed against uninvolved persons to achieve the set goals" [2]. Globalization has contributed to the development of terrorism, making states more interconnected, losing borders and increasingly demanding to protect their interests and security. In addition to deepening economic and social disparities, globalization also brings uneven use and use of natural resources, illegal migration of the population, organized crime and, last but not least, international terrorism.
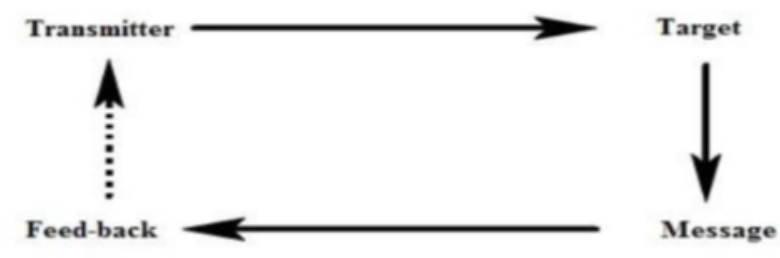

Figure 1. Terrorism communication square [5]

\section{DEVELOPMENT PHASES OF CHEMICAL TERRORISM}

Terrorism has evolved from national to international to contemporary global. The first form of development is national terrorism. It is planned and implemented within one state to enforce fundamental changes in its internal policies. Two features are typical for national terrorism. The first is targeted killing (attacks on politicians, high military or police dignitaries), the second is calling attention, the so-called "demonstrative terrorism". [3]

Another developmental form of terrorism is international terrorism, whose attacks cross national borders and reach targets in another state. The origin of the second stage can be traced back to the 1960s. For example, terrorists use the hijacking of airliners with a large number of passengers on board to blackmail political figures. Here, the aim is to kill civilians and then attract the attention of the international public. [4]

The last stage of development is global terrorism, which seeks to promote changes in international relations at a global level. It began to be talked about it in the context of the attacks of September 11, 2001. The cause of the threat is the worldwide existence of terrorist 
groups. However, it cannot be said that the onset of one stage ends all manifestations of the previous stages. [5]

\section{USE OF CHEMICALS TO ATTACK}

Chemical terrorism is a type of terrorism where a chemical is used as a tool to conduct an attack that endangers the health and lives of people. [6] The ability of chemical substances to adversely affect biological objects and thereby endanger their existence is based on their biological activity which can generally be understood as a hazard. Chemicals can be dangerous to biological objects in different ways. In the case of chemical terrorism, the primary hazard of a chemical is toxicity; the biological object is human. Terrorism must not always be understood as having a direct effect on poison. The subject of a chemical terrorist attack may be food base (agroterrorism), environment (ecoterrorism). [6]

Unfortunately, chemical terrorism against the population or other "vulnerable targets" has become a real threat to the contemporary world. It is well known that terrorists can use any "appropriate" weapons or means, including weapons of mass destruction (chemical, bacteriological, biological, radiological and toxin weapons, and in the foreseeable future, nuclear weapons or their destructive charges). [6] Abusive substances for terrorist attacks include mainly sarin, cyclosarin, soman, tabun, sulfur mustard, chlorine, ammonia, phosgene, hydrogen cyanide, and many others.

The first tests of chemical weapons were taken before the outbreak of the First World War. A breakthrough in their use occurred on April 22, 1915, when German troops used chlorine in the gaseous form prepared by German professor Fritz Haber against French soldiers. Around 180 tons of chlorine gas was discharged, affecting 15,000 French soldiers, of whom 5,000 died within three days. [6]

The overview of the use of all types of poisonous substances on World War I battlefields is extensive. About 45 kinds of poisonous substances were used on the battlefields, of which 18 were deadly and 27 irritating to varying degrees. The most dangerous were mainly chlorine, phosgene, diphosgene, hydrogen cyanide and mustard. 92,000 soldiers were killed in the war, up to $1,300,000$ soldiers were affected. [7]

\section{SOURCES OF CHEMICAL TERRORISM}

One of the most likely sources is own production. By this, we primarily mean the misuse of dangerous industrial toxic substances. Experts assume that the preparation of chemical weapons is relatively easy. Another potential source may be already discarded chemical weapons which are stored in military bases or stores and were destined for destruction according to international agreements. We find a higher risk of abuse in countries that have not signed the conventions. For this reason, it is assumed that these countries possess chemical weapons or other WMD. [8] An example could be sunk chemical munitions at the bottom of the sea as a remnant of improper disposal. This can be found in the Baltic Sea and elsewhere in Europe and the US, as there are places all over the world where chemical weapons have been dropped once into the seas and oceans. [9]

Chemical weapons and chemical warfare agents:

Fighting Chemicals (BCHL) are organic chemical compounds that can be used for mass destruction or incapacitation. Substances that do not belong to poisons from a pharmacological point of view, but cause temporary disability or exhaustion of living force (irritant and psychoactive) are considered to be such substances. The toxicity of chemicals varies considerably. Some are acutely toxic, others at all and have different effects on the body. The harmfulness of a chemical is dependent on:

- its toxicity,

- chemical concentration,

- substance entry gate,

- duration of exposure. [10]

Different aspects can be applied in the division of chemical warfare agents which have changed differently in connection with the gradual development of chemical weapons. The primary classification is according to the state of the chemical warfare agents under normal conditions (gaseous, liquid and solid state). [11]

The physical, chemical and toxic properties of generally hazardous chemicals are very significant and significantly affect the possible use and behavior of all hazardous toxic chemicals in different environments (air, water, soil).

These features include:

- physical properties: melting point and boiling point, saturated vapor stress, volatility, vapor density, solubility, surface tension, density, viscosity, thermal expansion, thermal stability,

- chemical properties: hydrolysis, oxidation, chemical stability, reactivity, thermal stability, stability to packaging materials,

- toxic properties: toxicity, speed of action, mechanism of action, detoxification of the substance in the body, medium threshold concentration and others. [7]

Persons may be affected by chemical warfare agents in the following ways:

- respiratory tract or inhalation,

- through the skin or percutaneously,

- ingesting contaminated food or liquids,

- their injuries. [12]

- charged battery, depending on the selected flow rate

\section{DEVELOPMENTAL STAGES OF TERRORISM}

The term population protection means performing tasks in the area of planning and subsequent performance of activities that should prevent the occurrence of possible emergencies and crises or states, ensuring preparedness and determining procedures for their resolution. 
The main tasks of population protection include the provision of warning, shelter, evacuation, individual and collective protection and emergency survival.

The main measures of population protection are:

- establishment and operation of a system of warning and informing the population and notifying stakeholders;

- timely and reliable transmission of information about a real or imminent emergency, preparation and use of individual protection or improvised means to protect the respiratory organs and body surface;

- preparation of shelters and organization of shelters in permanent and improvised shelters,

- providing medical assistance and sanitary measures to prevent and eradicate epidemics;

- prevention and disposal of leaks of dangerous substances, explosions and fires,

- identifying and rescuing vulnerable and disabled people;

- provision of a substitute and emergency supplies of drinking water, food, energy, sanitary and disinfectants, humanitarian and other forms of assistance,

- safeguarding public order and security, closing the affected and vulnerable

- space, regulation of movement of persons and transport,

- the preservation of property, cultural values, livestock and domestic animals,

- Emergency response and other activities as required. [8]

\section{DETECTION AND IDENTIFICATION OF DANGEROUS SUBSTANCES}

One of the essential measures to protect the population from the consequences of chemical terrorism is to quickly, correctly and effectively detect and identify dangerous chemicals. An integral part is a chemical research which is one of the chemical measures after the emergency, which includes the terrorist use of BCHL. It is a set of activities leading to the detection, characterization, identification or determination of BCHL. All other activities aimed at minimizing the consequences of MU are derived from the results of chemical research. The chemical survey aims to obtain data to assess the hazard of the substance, as well as information needed to take measures to protect the population and intervention units and to decide how to carry out rescue and decontamination work. [13]

\section{CHEMICAL TERRORISM}

The following groups may be active substances suitable for chemical terrorism:

- chemical warfare agents that are still stored in large quantities despite the convention on their ban,

- chemicals commonly used in the chemical, pharmaceutical and other industries, particularly phosgene $(\mathrm{CG})$ and fast-acting and more toxic hydrogen cyanide (AC);
- starting products and semi-finished products for chemical and other production, from which chemical warfare agents can be produced without significant problems. [14]

Most substances, under consideration as a means of chemical terrorism, can maintain their destructive properties for various periods of destructive action. [15]

Toxicological properties of chemical warfare agents concentration. Concentration is a quantity that numerically characterizes the composition of a mixture. It is the ratio of the substance of interest to the total amount of solution or mixture. [16]

- median threshold concentration PCt50 - the concentration of BCHL that, at time $t$, causes the development of threshold symptoms in $50 \%$ of affected,

- median incapacitating ICt50 concentration - the concentration of BCHL that at the time $t$ causes temporary incapacitation of the affected person,

- mean effective concentration ECt50 - the concentration of BCHL, at which at the time $t$ in $50 \%$ of the affected persons, the full toxic effect is manifested and the victim is put out of operation,

- mean lethal LCt50 concentration - the concentration of BCHL that kills $50 \%$ of the affected after time t.

Toxicological properties of chemical warfare agents dose

The dose is understood as the amount of chemical (xenobiotics) that penetrates the body.

- PD50 Medium Threshold Dose - a dose that is capable of inducing damage thresholds in $50 \%$ of those affected;

- Medium incapacitating dose ID50 - BCHL dose that temporarily incapacitates $50 \%$ of the affected

- the medium effective dose of ED50 - a dose of BCHL that is capable of producing a full toxic effect in $50 \%$ of the victims;

- median lethal dose LD50 - a dose of BCHL that kills $50 \%$ of the affected. [16]

\section{HAZARDOUS CHEMICALS AND MARTIAL CHEMICALS SELECTED FOR MODELING}

\section{Chlorine ( $\mathrm{Cl}$, chlorine gas $\mathrm{Cl2}$ )}

Chlorine is a yellow-green gas heavier than air with a characteristic sharp (pungent) odor. In the gaseous state, it is breathable and toxic. In the classification of hazardous substances it belongs to highly toxic gases, it is also explosion-proof and non-flammable. Chlorine is also characterized by high reactivity because it reacts with a large number of elements. Contact with some flammable substances forms explosive mixtures, e.g. hydrogen. Chlorine belongs to the group of suffocating warfare agents. [17]

\section{Ammonia (NH3)}

Ammonia (ammonia) is a colorless gas of sharp, pungent and irritating odor, easily liquefied. It is a dangerous toxic and alkaline substance that is lighter than air. When vaporized from a liquid state, they form cold mists that are heavier than air. Ammonia is a corrosive toxic gas used in the production of fertilizers, plastics, etc. Due to 
its thermodynamic properties, ammonia is used as one of the refrigerants (anhydrous ammonia - ice rinks). [18]

\section{Phosgene (COCl2)}

Phosgene is a poisonous liquid that quickly changes into a gaseous state. It is characterized by the smell of rotting leaves or freshly mown hay. It belongs to the group of very toxic irritant gases. Phosgene gas is heavier than air. It is a non-flammable non-reactive substance at a standard temperature. Gas evolution produces toxic corrosive mixtures and cold fog heavier than air. He belongs to the suffocating annoying BCHL. [18]

\section{Hydrogen cyanide (HCN)}

Hydrogen cyanide is one of the fastest acting poisons. It is a colorless volatile liquid with a typical bitter-almond odor. It is a weak acid. When dissolved in water, it is partially converted into a cyanide ion, which is toxic. Hydrogen cyanide vapors are flammable and potentially explosive. The substance is well soluble in water and organic solvents. Despite its high efficiency, it is not suitable as a combat gas, as it quickly escapes into the atmosphere. It is dangerous in enclosed rooms and near leakage sites. [19]

\section{Hydrogen chloride ( $\mathrm{HCl}$ )}

Hydrogen chloride is a compound of chlorine and hydrogen. It is a colorless gas with a pungent odor. It forms a white mist on humid air and dissolves well in water. It has corrosive and aggressive effects as a gas. It is easy to liquify but is stable at higher temperatures. Hydrogen chloride is an essential raw material in the industry. Naturally, it enters the environment, for example, by volcanic activity or emissions from industrial plants, from the combustion of coal, plastics, and waste. It contributes to the formation of acid rain. The aqueous hydrogen chloride solution is hydrochloric acid. [20]

\section{Sarin (C4H10F2P)}

Pure sarin is a colorless, odorless, mobile liquid. It is a substance included in the arsenal of chemical weapons. Among the NPLs, it is the most volatile substance and, at the same time, the most soluble in water and organic solvents. Its production was banned by the International Convention on the Prohibition of Chemical Weapons. Sarin was used in two major terrorist attacks in Japan in 1994 and 1995. [20]

\section{Chlorocyanate (CNCl)}

It is a colorless, volatile gas that belongs to generally toxic chemical warfare agents. It has a sharp, irritating, chlorine-like odor and high toxicity. Its vapors are extremely irritating and corrosive. Vapors may be heavier than air and, in the event of leakage, the spreading takes place in the ground layers. The substance is soluble in water and alcohol. [21]

\section{TEREX - TERRORIST EXPERT}

The paper uses the outputs from modeling software. Models are a certain representation of the predicted reality. The assumed fact, in this case, the process (modeling the development of the chemical situation), is subject to modeling. [22] A model usually displays only those properties that the creator or future user will be interested in in a particular case. Directly put, modeling is an activity that imitates a certain part of reality.

Modeling and simulation of emergencies related to hazardous chemicals are just one of many phases of crisis management. Outputs from modeling are also used in the prevention, planning, and solution of given incidents. [23]

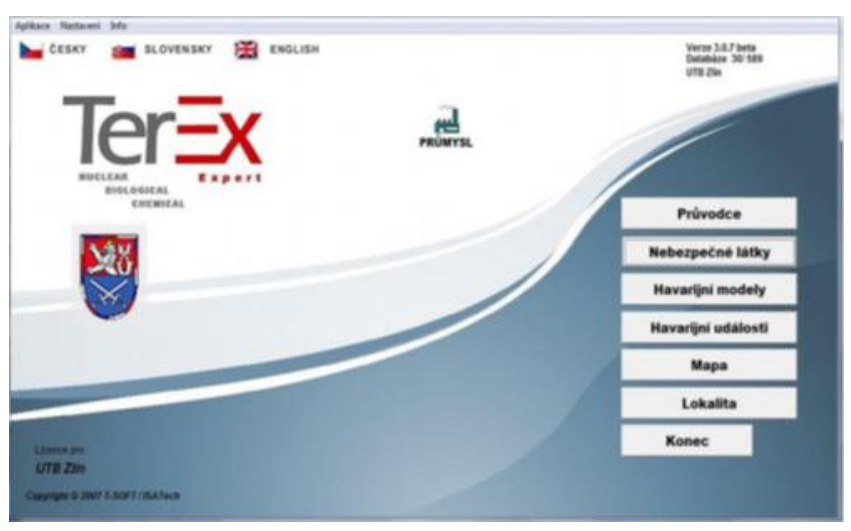

Figure 2. TerEx program [23]

T-SOFT's TerEx or TERRORIST EXpert is a software tool designed to instantly assess the consequences of industrial accidents, hazardous substance releases, terrorist attacks, and chemical weapons attacks. It is mainly used by IRS units during intervention or by other authorities or institutions as a risk analysis tool for emergency planning. The program also allows the user to display graphical results in maps. The program is based on nine MU models covering various types of accidents and terrorist attacks, as well as a list of approximately 900 hazardous substances. [23]

Modeling and simulation of emergencies related to hazardous chemicals are just one of many phases of crisis management. The outputs from modeling are also used in the prevention, planning, and resolution of given emergencies. TerEx or TER-Terrorist EXpert from TSOFT is a software tool used to instantly estimate the consequences of industrial accidents, leaks of dangerous substances, terrorist attacks, and chemical weapons attacks. It is used mainly by IRS units in the event of an intervention or by other bodies or institutions as a tool for risk analysis in emergency planning. The program also allows the user to display graphical results in maps. The basis of the program is nine MU models, which cover various types of accidents and terrorist attacks, as well as a list of approximately 900 dangerous substances.

\section{MODELING OF SELECTED HAZARDOUS INDUSTRIAL TOXIC CHEMICALS AND COMBATING CHEMICALS}

In the event of an extraordinary event related to the release of a dangerous chemical substance or in the case of the implementation of chemical terrorism, it is possible to use the TerEx program, which makes it possible to 
estimate the impacts incurred by the given MU. It proposes an optimal solution to the situation in connection with the given dangerous chemical substance. The program is connected to a geographic information system, which allows the results to be displayed in maps. TerEx determines the distance to which evacuation of persons is necessary and the distance to be investigated for toxic concentration. For explosive substances, the program evaluates the distances of people at risk of direct clouding or serious injury, and to what distance there is serious damage to buildings or people inside buildings through window glass.

\section{MODEL SITUATION EVALUATION}

Since the version of TerEx allows only the modeling of some chemical warfare agents, only two chemical warfare agents were modeled and then compared. As in the previous modeling of industrial hazardous substances, the same input data for both substances was determined for BCHL, and the comparison of individual substances was based on output data. For chemical warfare agents, the PLUME model was chosen - slow evaporation of liquid from the puddle to the cloud. In this type of model, the area range is limited from 1 to $500 \mathrm{~m} 2$.

Comparing all the output data, cyanogen chloride appears to be more effective than sarin. Chlorocyanate is a highly toxic substance approximately 13 times more toxic than chlorine. It has a sharp pungent odor and causes tearing. It is highly volatile, and inhalation poisoning is very fast on the body. It causes the body's inability to use oxygen and can cause rapid death due to central palsy. The toxicological effects of cyanogen chloride are quite similar to hydrogen cyanide. The stability of the fabric in the field in the summer months ranges from 10 to 15 minutes, in the winter months around 20 minutes. [11]

Sarin has been misused in the past for chemical attacks, and its effects are verified. Among the NPLs, it is the most volatile substance, therefore when the liquid evaporates freely, it is the most appropriate form for misuse by chemical terrorism. Vapors and fine aerosol particles of liquid sarin are immediately absorbed by the respiratory organs, the conjunctiva, and the digestive tract. The effect on the body is immediate. The essence of the toxic effect is an intervention in the mechanism of transmission of nerve impulses. Inhalation poisoning with lethal doses of sarin causes death within 1-10 minutes. Rapid poisoning with fatal consequences occurs in case of contact with liquid sarin.

Sarin was classified as a weapon of mass destruction, and its production or storage was prohibited by the International Chemical Weapons Convention. Both substances can be misused in the realization of chemical terrorism, as they are volatile and very toxic substances with lethal effects on the body. Any use of chemical warfare agents or weapons is prohibited by international agreements, and most countries are committed to destroying them. World powers Russia and the US possessed the largest stocks of chemical warfare agents and weapons.

In 2017, Russia announced that it had liquidated all its chemical weapons. It was 44 thousand tons. The US wants to get rid of the rest of the chemicals by 2023. It is easier to produce chemical weapons than to dispose of them. The availability of chemicals is relatively easy nowadays, and further production is not excluded. Destruction is 10times more expensive than production. Disposal is by chemical neutralization or combustion. In both cases, it is necessary to build specialized operations and protect the environment. [24]

\section{EVALUATION AND PROPOSAL TO IMPROVE THE SITUATION OF THE PROTECTION OF POPULATION AGAINST CHEMICAL TERRORIM}

In most cases, a chemical terrorist attack is prepared long in advance and is a completely unexpected event for its victims. Any chemical that is available to terrorists has sufficient toxicity, and is practically applicable to the purpose or motive can be used for the attack. In order to eliminate the impact of a terrorist attack, it is crucial to secure all components involved in the liquidation of consequences in the event of a given incident. [6] Within the Czech Republic, it is an integrated rescue system (IRS CR), consisting of members of the Fire Rescue Service of the Czech Republic, the Police of the Czech Republic and the emergency medical service. Their readiness determine how much damage the attack will do. No society can be perfectly prepared for this form of organized violence, but it must be prepared as well as possible. In my opinion, the question of assessing the population's awareness of protection against chemical terrorism is relatively complex. The security environment is constantly changing, evolving, and the ability to maintain security is becoming demanding increasingly. [24]

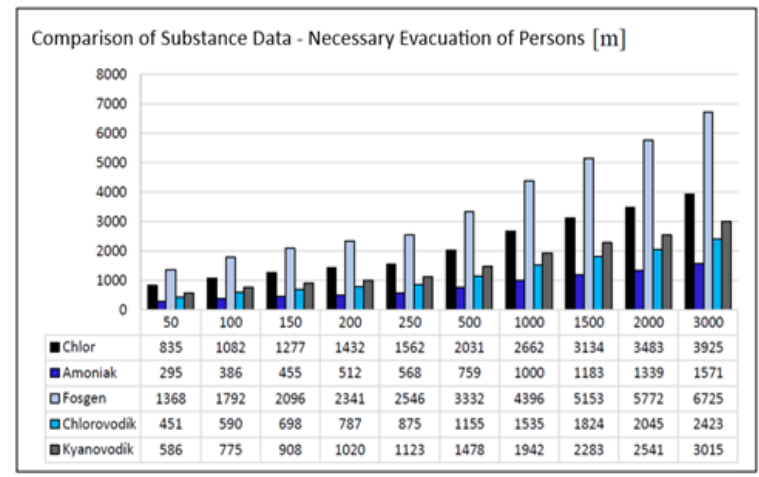

Figure 3. Comparison of data in dependence on wind speed [Own]

In response to a rapidly changing security environment, there is the creation of security documents and strategy of the Czech Republic. Thanks to these documents and constitutional laws, the continuous 
development of the population protection sector can be observed. I think that the system of population protection is set up quite well in the Czech Republic. It goes without saying that some shortcomings can be better regulated. I think that the level of state preparedness for a chemical terrorist attack cannot be assessed solely on theoretical bases. Nevertheless, the actual state of the population protection system will be clarified only after the attack itself. If the state does not have adequate experience with the attack, we cannot speak of $100 \%$ preparedness and sufficient security.

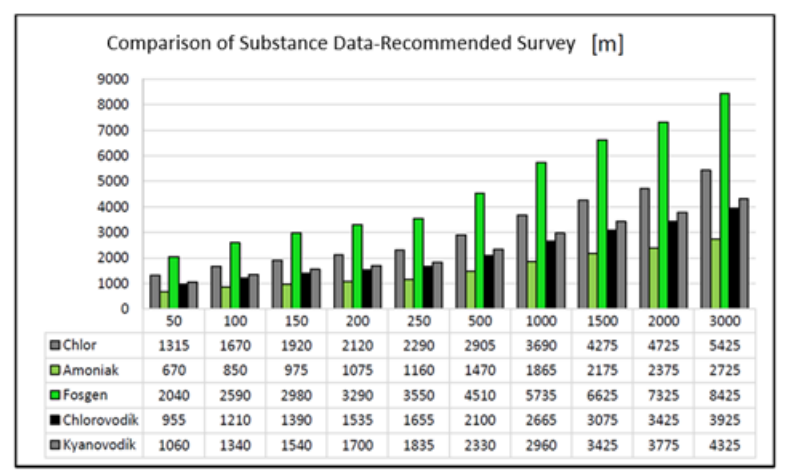

Figure 4. Comparison of data depending on wind speed [Own]

For modeling hazardous substances, it sets the same input data for all substances. The comparison of individual chemical substances was performed based on output data. It was a necessary evacuation of people, ie a threat to people with a toxic substance, which is quantified in the program by the unit of measurement. Another output was the recommended survey of the toxic concentration at a distance from the site of the leak (also in meters). In all the graphs, we can see that phosgene, together with chlorine, is one of the demonstrably most dangerous substances, both in terms of the necessary evacuation and in the recommended survey. Otherwise, ammonia and hydrogen cyanide reach low values. However, this does not mean that these are nonhazardous substances. Ammonia is a flammable, explosive, and highly toxic gas and, due to its frequency of use, appears to be one of the most likely exploitable substances for the possible realization of chemical terrorism. Anhydrous ammonia is used as a cooling medium in winter stadiums, in large-capacity refrigeration plants, or the food industry. Furthermore, the substance is used as a fertilizer, in the pharmaceutical, chemical, or textile industries. It follows that the availability of a given substance is essentially simple.

\section{SUGGESTIONS TO IMPROVE THE SITUATIPN}

The most significant benefit would be the broader involvement of citizens in the population protection system. However, the company will not achieve this through activities such as distributing leaflets or organizing one-off events. Every citizen cannot be interested in this issue, which results in ignorance of fundamental information about the area. More significant knowledge and interest of the population in the issue could partially ease the situation in the event of an emergency.

One of the possible solutions could be more recent clips or spots to be included in television or instead of commercials. In the past, the series "Happiness Wishes Prepared" was published, which contained condensed information for the population to inform about possible dangers and familiarize the population with best practices. [25]

More modern clips would have to be filmed to attract the attention of the viewer and include concise, practical information and emergency procedures. The attention of the viewer could be aroused by demonstrations, specialists in their field or familiar faces. Television spots should be included in prime times to achieve high viewership.

The development of the protection of the population against chemical terrorism can be supported in cooperation with other states in the areas of experience, prevention, liquidation of consequences and preparedness. The above proposals are just a few of the possible solutions to improve the population protection system and to integrate the population more fully into the system.

At present, there is no system for preparing all groups of the population for emergencies and crises. This system should include regular and systematic preparation of the population for possible chemical terrorist attacks. The preparation of the population is not sufficiently supported by legislation yet, and the question is whether there will be any significant improvement in the future.

\section{CONCLUSION}

The aim of the article was to elaborate a sufficient theory concerning the protection of the population against chemical terrorism. Terrorism is serious and complex problem to solve worldwide. Moreover, terrorism has become an efficient tool for promoting its interests. Connection of the world into one great community results in a greater number of threats that individual states face directly or indirectly. During the writing of the article, I concluded that population protection and overall preparedness for a possible chemical terrorist attack are still in the development phase. Therefore, it is necessary to pay increased attention to the threat. The paper presents a theoretical basis that serves as an introduction to the whole issue.

The purpose of any security system is to maintain order in the state and effectively deal with crises. Security measures can maintain a certain level of security and provide sufficient protection for the population. The 
security environment varies depending on the situation, both inside and outside the state. Therefore, the continuous innovation of this issue is in place. The common objective of all Member States is, above all, to prevent conflicts and, in the event of their occurrence, to deal effectively and consistently with their consequences. The conclusion of the article defines chemical terrorism and the protection of the population against chemical terrorism.

The aim of this section was to briefly outline essential information related to these terms. The real threat is the misuse of common industrial chemicals, discarded chemical weapons destined for destruction under the relevant international conventions, or the potential misuse of chemical weapons from states that have not ratified it yet. It is assumed that these countries may still own some chemical weapons. Terrorist attacks on chemical and petrochemical facilities are also a major threat.

The rapid and seamless exchange of information over computer networks enables terrorists to obtain the information they need quickly and practically without risk. This activity makes it much easier for terrorists, so this threat is gaining in importance every day. The legal standards, from which specific crisis management measures can be derived from existing security strategies and other documents, are the starting point for the success and quality of population protection. Last but not least, an important factor is an adequate information for citizens, which contributes to a higher degree of preparedness for the civilian population. In addition, model situations were processed through a software program.

The TerEx program was chosen for modeling. A total of seven chemicals, which were characterized in the practical part before modeling, were selected. The output of the modeling is data entered into the table and their subsequent comparison through graphs. Substances were divided into industrial chemical and chemical warfare, and the results were briefly evaluated at the end. It can be concluded that under the assumptions and conditions used in modeling, these substances can be considered suitable for the implementation of a terrorist chemical attack. The use of these substances is appropriate when the aim is to reach a large number of people. When choosing another target (e.g. intimidation or exclusion), the choice of another chemical is considered. I confirm that the misuse of chemical weapons or chemicals is a serious threat to the 21 st century.

Another way to evaluate the system of protection of the population against chemical terrorism and to suggest possible ways to improve the issue. Individual proposals are one of many solutions to contribute to the perspective of population protection. Every citizen, security forces and crisis management authorities should be adequately prepared for emergencies of this type. It is, therefore, crucial to pay attention to safety measures and not to take anything lightly.

\section{ACKNOWLEDGMENT}

This research was based on the support of the Internal Grant Agency of Tomas Bata University in Zlín, the IGA
/ FAI / 2021/002 project and the Department of Security Engineering, Faculty of Applied Informatics.

\section{REFERENCES}

[1] Terminological dictionary - crisis management and state defense planning. Praha, 2016. [online]. Available: https://www.mvcr.cz/clanek/terminologicky-slovnik-krizoverizeni-a-planovani-obrany-statu.aspx

[2] FILIPEC, O., The phenomenon of terrorism: the Czech perspective. 1st edition. Olomouc: Palacký University in Olomouc, 2017. ISBN 978-80-244-5040-7.

[3] EICHLER, J., Terrorism and wars in the time of globalization. 2., dopl. Praha: Karolinum, 2010. ISBN 978-80-246-1790-9.

[4] KAVICKÝ, V., Štefan JANGL and Libor GAŠPIERIK. Terrorism threat of the times. Bratislava: Citadella, 2015. ISBN 978-8089628-84-1.

[5] HENDERSON, Harry. Terrorism. New York: Facts on File, 2001. ISBN 0816042594.

[6] FUSEK, J. a J. PATOČKA. Chemical agents and chemical terrorism [online]. In: . Cent Eur J Publ Health, b.r., s. 3 [cit. 201810-31].

[7] KLABAN, V., KLABANOVA S., History and Present of Chemical Weapons: Scientific and Professional Conference: 27.28. May 2015, Use of Chemical Weapons and Misuse of Industrial Chemicals Uherské Hradiště, Czech Republic. Release first. In Zlín: Tomas Bata University, 2015. ISBN 978-80-7454-491-0.

[8] MIKA, O., J and Milan Ř́lHA. Protection of the population against the consequences of the use of weapons of mass destruction. Vyd. 1. Prague: Naval Academy of the Czech Republic, 2011. ISBN 978-80-87103-31-9.

[9] FILIPEC, O., Introduction to WMD. Olomouc: Palacký University in Olomouc, 2013. ISBN 978-80-244-3810-8.

[10] The National Academics Of Sciences, . Chemical Attack Fact Sheet: Warfare Agents, Industrial Chemicals and Toxins [online]. In: . b.r. [cit. 2018-11-16]. Available: https://www.dhs.gov/publication/chemical-attack-fact-sheet

[11]

[12] MIKA, O., ZEMAN, M., and POLÍVKA, L.,. Basics of protection against weapons of mass destruction. Vyd. 1. Brno: Brno University of Technology, Faculty of Chemistry, 2011. ISBN 97880-214-4263-4.

[13] BRZYBOHATÝ, M., Mika, J., Protection against chemical and biological terrorism. Vyd. 1. Praha: Vydavatelství PA ČR, 2007. ISBN 978-80-7251-271-3.

[14] PITSCHMANN, V., Chemical Weapons and Protection against Them. Praha: Manus, 2011. ISBN 978-80-86571-09-6.

[15] HORÁK, R., Mika, J., Population protection against terrorism. Vyd. 1. Brno: University of Defense, 2007. ISBN 978-80-7231295-5.

[16] MATOUŠEK, J., Mika, O., VIČAR D., VIČAR. New terrorist threats: chemical, biological, radiological and nuclear terrorism: textbooks. Brno: University of Defense, 2005. ISBN 80-7231-0372.

[17] DRÁPAL, S., Basic aspects of population protection against the consequences of chemical terrorism in the Czech Republic. Brno, 2013. Bachelor thesis. Technical University Brno. Thesis supervisor Otakar Jiří Mika.

[18] LACINA, P., MIKA, O., ŠEBKOVÁ, K., Hazardous chemicals and mixtures. Brno: Masaryk University, Research Center for Toxic Compounds in the Environment, 2013. Recetox. ISBN 97880-210-6475-1.

[19] FLORUS, S., Toxicological aspects of chemical accidents [online]. České Budějovice: University of South Bohemia, 2008 [cit. 2018-11-16]. ISBN 978-80-7394-106-2.

[20] HORÁK, R., DANIELOVÁ, L., JUŘÍČEK, L., and ŠIMÁK, L., Company protection policy. Release first. Ostrava: Key Publishing, s.r.o., 2015. Monographs (Key Publishing). ISBN 97880-7418-236-5.

[21] PETRLÍK, J., VÁLEK, P., Hydrogen chloride [online]. [cit. 201902-08]. Available: https://arnika.org/chlorovodik

[22] NIOSH, . Cyanogen chloride. In: Centers for Disease Control and

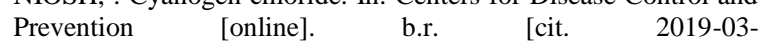
11].Available:https://www.cdc.gov/niosh/ershdb/emergency responsecard_29750039.html 
[23] HORÁK, J., Tool for using software for quick estimation of consequences of accidents and terrorist attacks [online]. In:. b.r. [feeling. 2019-03-25]. Available: https://docplayer.cz /41525929Pomucka-pro-vyuzivani-softwaru-pro-rychly-odhad-nasledkuhavarii-a-teroristickych-utoku.html

[24] BARTA, J., LUDIK, T., TerEx - modeling and simulation. Brno: University of Defense, 2012

[25] ENVIWEB,. Disposal of chemical weapons [online]. In:. b.r. [feeling. 2017-05-31]. Available: http://www.enviweb.cz/44695

[26] MOŠKVANOVÁ, D., Population protection against chemical terrorism. Uherské Hradiště, 2016. Bachelor thesis. Faculty of
Logistics and Crisis Management. Thesis supervisor Otakar Jiř́ Mika.

Copyright (C) 2020 by the authors. This is an open access article distributed under the Creative Commons Attribution License (CC BYNC-ND 4.0), which permits use, distribution and reproduction in any medium, provided that the article is properly cited, the use is noncommercial and no modifications or adaptations are made.

\section{Columns on Last Page Should Be Made As Close As Possible to Equal Length}

\section{Authors' background}

\begin{tabular}{|l|l|l|l|}
\hline Your Name & Title $^{\star}$ & Research Field & Personal website \\
\hline Barta & $\begin{array}{l}\text { Phd } \\
\text { candidate }\end{array}$ & $\begin{array}{l}\text { Population } \\
\text { Protection, } \\
\text { Emergency } \\
\text { Management, } \\
\text { High } \\
\text { Contagious } \\
\text { Diseases }\end{array}$ \\
\hline Martin & Associate & $\begin{array}{l}\text { Critical } \\
\text { infrastructure, } \\
\text { emergency } \\
\text { professor }\end{array}$ & $\begin{array}{l}\text { management, } \\
\text { soft targets }\end{array}$ \\
\hline
\end{tabular}

*This form helps us to understand your paper better, the form itself will not be published.

*Title can be chosen from: master student, Phd candidate, assistant professor, lecturer, senior lecturer, associate professor, full professor, research, senior research 